\title{
Machine Learning-Based Modeling with Optimization Algorithm for Predicting Mechanical Properties of Sustainable Concrete
}

\author{
Muhammad Izhar Shah $\left(\mathbb{D},{ }^{1}\right.$ Shazim Ali Memon $\left(\mathbb{D},{ }^{2}\right.$ Muhammad Sohaib Khan Niazi, ${ }^{3}$ \\ Muhammad Nasir Amin $\left(\mathbb{D},{ }^{4}\right.$ Fahid Aslam $\left(\mathbb{D},{ }^{5}\right.$ and Muhammad Faisal Javed ${ }^{1}{ }^{1}$ \\ ${ }^{1}$ Department of Civil Engineering, COMSATS University Islamabad, Abbottabad Campus, Abbottabad 22060, Pakistan \\ ${ }^{2}$ Department of Civil and Environmental Engineering, School of Engineering and Digital Sciences, Nazarbayev University, \\ Nur-Sultan 010000, Kazakhstan \\ ${ }^{3}$ Civil Engineering Department, Qurtuba University of Science and Information Technology, Dera Ismail Khan, Pakistan \\ ${ }^{4}$ Department of Civil and Environmental Engineering, College of Engineering, King Faisal University (KFU), P. O. 380, Al-Hofuf, \\ Al Ahsa 31982, Saudi Arabia \\ ${ }^{5}$ Department of Civil Engineering, College of Engineering, Prince Sattam Bin Abdulaziz University, Al-Kharj 11942, Saudi Arabia
}

Correspondence should be addressed to Muhammad Izhar Shah; mizhar@cuiatd.edu.pk and

Shazim Ali Memon; shazim.memon@nu.edu.kz

Received 1 December 2020; Revised 4 February 2021; Accepted 18 February 2021; Published 4 March 2021

Academic Editor: Junfei Zhang

Copyright (c) 2021 Muhammad Izhar Shah et al. This is an open access article distributed under the Creative Commons Attribution License, which permits unrestricted use, distribution, and reproduction in any medium, provided the original work is properly cited.

In this research, multiexpression programming (MEP) has been employed to model the compressive strength, splitting tensile strength, and flexural strength of waste sugarcane bagasse ash (SCBA) concrete. Particle swarm optimization (PSO) algorithm was used to fine-tune the hyperparameter of the proposed MEP. The formulation of SCBA concrete was correlated with five input parameters. To train and test the proposed model, a large number of data were collected from the published literature. Afterward, waste SCBA was collected, processed, and characterized for partial replacement of cement in concrete. Concrete specimens with varying proportion of SCBA were prepared in the laboratory, and results were used for model validation. The performance of the developed models was then evaluated by statistical criteria and error assessment tests. The result shows that the performance of MEP with PSO algorithm significantly enhanced its accuracy. The essential input variables affecting the output were revealed, and the parametric analysis confirms that the models are accurate and have captured the essential properties of SCBA. Finally, the cross validation ensured the generalized capacity and robustness of the models. Hence, the adopted approach, i.e., MEP-based modeling with PSO, could be an effective tool for accurate modeling of the concrete properties, thus directly contributing to the construction sector by consuming waste and protecting the environment.

\section{Introduction}

The construction industry consumes one-third of the world's energy and is a significant contributor of greenhouse gas emission to the environment [1]. Concrete is the most commonly used construction material. A single ton of concrete releases about 0.13 ton of carbon dioxide [2,3]. In order to move towards sustainability, the concept of green concrete is getting popular to reduce the adverse effects of concrete. Green concrete is produced by replacing the conventional cementitious material with some waste as replacement of cement. Commonly used materials are fly ash, waste foundry sand, blast furnace slag, glass, metakaolin, rice husk ash, recycled aggregate, and bagasse ash [4]. Utilization of such materials is considered as low-carbon substitute to conventional construction materials. Sugarcane bagasse, which is an agricultural waste obtained after crushing and extraction, is used as fuel in the sugarcane industry [5]. Each ton of sugarcane generates approximately 26 percent of bagasse and 0.62 percent of residual ash [6]. 
The obtained ash is disposed by dumping in landfills and poses serious environmental issues [7]. Therefore, alternative and eco-friendly utilization methods of sugarcane bagasse ash (SCBA) are being discovered in the construction sector. Various research studies have concluded the viable use of SCBA in concrete as a cement replacement with a significant increase in mechanical properties of concrete. Chusilp et al. [8] reported higher compressive strength and lower permeability when concrete contained 20\% SCBA by weight of cement. Sobuz [9] reported that maximum strength of SCBA concrete was obtained when cement was replaced with $10 \%$ of SCBA. Jagadesh et al. [10] reported that the strength of concrete made with $30 \%$ raw SCBA as a cement replacement reduced by almost 50\%. The same authors reported about $28 \%$ increase in the strength of concrete when cement was replaced with $10 \%$ processed SCBA. The increase in strength was attributed to finer silica which reacted with calcium hydroxide to form additional $\mathrm{CSH}$. Also, the finer SCBA particles filled voids and increased the packing density, which in turn increased the compressive strength of concrete. Bahurudeen et al. [11] reported higher strength of SCBA concrete as compared to normal concrete. Maximum compressive strength was achieved when cement was replaced with 10\% SCBA. Strength reduction was linked with the dilution effect of the matrix caused by higher percentage replacement. Several researchers have also concluded that the utilization of SCBA also results in improved durability properties such as chloride penetration, chloride conductivity, water sorptivity, and water permeability $[8,12-14]$. The above discussion highlights the point that SCBA concrete behaves differently at low and high replacement levels. This behavior could be attributed to several aspects, i.e., composition and dosage of SCBA, mix proportions, and the properties and type of the concrete constituents. Therefore, it is essential to correlate and figure out the factors influencing the mechanical properties of SCBA concrete, which, in turn, will have profound effect on the construction industry.

In order to address this issue, the unique features of artificial intelligence (AI) techniques such as random forest (RF), support vector machine (SVM), artificial neural network (ANN), gene expression programming (GEP), M5P, support vector regression (SVR), and convolution neural network (CNN) have been used to develop, correlate, and find the factors influencing the mechanical properties [15-19]. Zhang et al. [20] developed the RF model for the investigation of the hardened properties of synthetic-sand concrete. From results, it was found that RF showed reduced performance in comparison to other models. In a study conducted by Sun et al. [21], the authors utilized RF combined with an optimization algorithm for predicting the uniaxial compressive strength of rubberized concrete. The output of the study reported good accuracy of the model with a high correlation. Huang et al. [22] used the RF model along with beetle antenna search algorithm to predict the permeability of pervious concrete. The result of the study suggested improved performance of RF optimized model. ANN algorithm was used to model the compressive strength of lightweight concrete, foamed concrete, silica fume concrete, and high-performance concrete and elastic modulus of recycled aggregate concrete [17, 23-28]. A good correlation was observed in these studies for estimating the underlying concrete properties. However, the ANN is considered as black box algorithm, since it does not consider information or physical phenomena of the related problem [29]. Moreover, due to lack of parametric studies, the ANN models may not perform well on unseen datasets [30]. Recently, the advanced GEP technique was applied to predict the mechanical properties of SCBA and waste foundry sand concrete. Sensitivity and parametric analyses were performed to assess the performance of the models developed for mechanical properties $[4,31]$. In these studies, the results of the comparative study revealed superior performance of GEP over regression methods. However, the GEP was identified with certain limitations since it fails to consider a few deviating datasets for model development, thus reducing its range of applicability [4]. Such deviating datasets should be removed from both training and testing phases to improve the model performance. Furthermore, the GEP encodes only a single chromosome and is suitable for simple relationship of input and output variables [32].

Considering the above limitations of certain AI techniques, an advanced algorithm, i.e., multiexpression programming with particle swarm optimization (PSO-MEP), has been adopted to model the mechanical properties of SCBA concrete. MEP with optimization technique (PSO) has been rarely used in civil engineering field despite its distinguished features. The mechanical properties of SCBA concrete in terms of compressive strength (CS), splitting tensile strength (ST), and flexural strength (FS) were modeled using PSO-MEP to solve complex relationship. A large dataset was collected from the literature for model training and testing. The validity of the developed models was verified utilizing the results obtained from laboratory testing. Furthermore, the variable importance, parametric study, and cross validation were used to assess the robustness and accuracy of the developed models.

\section{Methods and Datasets}

2.1. Multiexpression Programming. A linear variant of machine learning, i.e., multiexpression programming (MEP), has been proposed recently. The individual entities can be represented as a variable length in $\operatorname{MEP}[32,33]$. The linear variants permit MEP to extricate the genotype and phenotype [34]. MEP is considered expedient over other techniques due to linear chromosomes and encoding multiple solutions in an individual chromosome. This unique feature allows to search in a wider space to gather the best possible solution. In comparison to genetic programming, the MEP applies simple decoding procedures and is given particular importance in case of unknown complexity of targeted expression [29]. MEP can handle exceptions such as invalid expressions, divide by zero, etc. MEP can handle exceptions such as invalid expressions and divide by zero and it transforms into arbitrary terminal symbol so that the process continues. This produces a margin in structure of chromosome 
during evaluation process [32]. The various steps involved in MEP process are shown in Figure 1. The MEP algorithm is similar to $C$ language and pascal compiler. The outcome of the MEP process is a combination of mathematical operators or variables in a linear string of instruction form [35].

2.2. Particle Swarm Optimization. Particle swarm optimization (PSO) is a computational technique mainly used for problem optimization to enhance a solution by iterative process given a set of quality measures. This technique was developed by Kennedy and Eberhart based on motion of bird flocking and schooling fish [36]. In PSO, a process is initiated with a population of arbitrary solutions and the generations are updated to search for optimal solution. This technique is widely used for problem optimization such as forecasting the compressive strength, image contrast enhancement, and evaluating energy performance of building $[37,38]$. In the present study, PSO was applied to fine-tune the hyperparameter of MEP and improve the modeling accuracy.

2.3. Modeling Database. A detailed dataset of different properties of SCBA concrete was collected from the published literature $[8-11,13,14,39-60]$. The collected datasets contained information about SCBA concrete at 28 days. Some of the aforementioned research studies used concrete cubes to determine the compressive strength of SCBA concrete. In order to get homogenous data, the cube strength was converted to cylinder strength according to the method suggested by Elwell and $\mathrm{Fu}$ [61]. The collected literature data were statistically analyzed to get the most influential parameters affecting properties of SCBA concrete. The statistical parameters of different variables used in modeling are given in Table 1 [62]. An extensive study of design codes revealed that different models are available correlating the mechanical properties of normal concrete with compressive strength [63-67]. Therefore, the water to cementitious ratio (W/C), proportions of bagasse ash (SCBA\%), fine aggregate content (FA), cement content (CC), and quantity of coarse aggregate (CA) are chosen as input for prediction of SCBA concrete mechanical properties. The formulation of compressive strength (CS), splitting tensile strength (ST), and flexural strength (FS) of SCBA concrete is considered to be a function of the following variables:

$$
\text { CS, ST, FS }=f\left(\frac{W}{C}, \text { SCBA } \%, \text { CA, CC, FA }\right) \text {. }
$$

2.4. Modeling Parameters for MEP. For developing a generalized relationship, several fitting parameters are required for MEP. The chosen parameters for MEP modeling are presented in Table 2. Basic mathematical operators were considered to get simple expressions. The trial and error method was adopted to get the fitting parameters [68]. The population size was used to specify the number of programs required in the population. High population can lead to

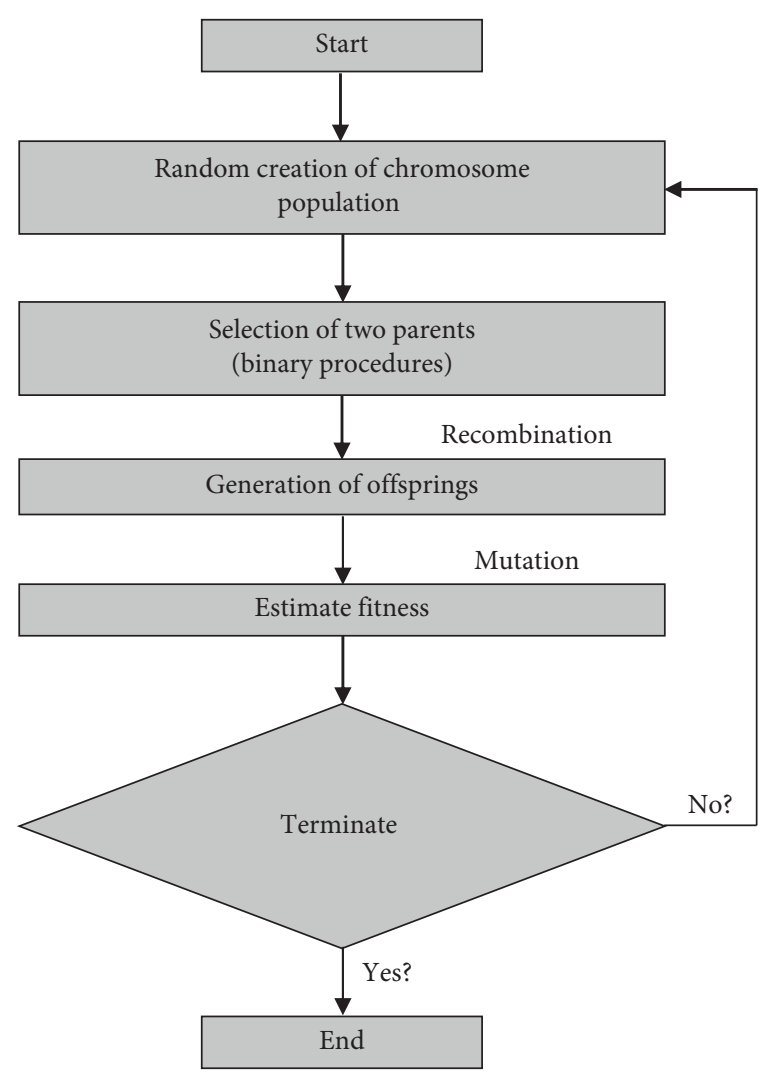

Figure 1: Schematic diagram of MEP technique.

TABLE 1: Statistics of the input parameters.

\begin{tabular}{lccccc}
\hline Parameter & W/C & CC & SCBA $\%$ & FA & CA \\
\hline Unit & - & $\mathrm{kg} / \mathrm{m}^{3}$ & $\%$ & $\mathrm{~kg} / \mathrm{m}^{3}$ & $\mathrm{~kg} / \mathrm{m}^{3}$ \\
Range & 0.3 & 444 & 50 & 614 & 772 \\
Min & 0.3 & 112 & 0 & 239 & 477 \\
Max & 0.6 & 555 & 50 & 853 & 1249 \\
Mean & 0.47 & 336.5 & 13.98 & 603.5 & 884.6 \\
SD & 0.074 & 98.5 & 10.46 & 232.1 & 392.3 \\
\hline
\end{tabular}

TABLE 2: Optimum parameter setting for MEP.

\begin{tabular}{lc}
\hline Parameters & Setting \\
\hline Number of subpopulation & 50 \\
Size of subpopulation & 250 \\
Code length & 40 \\
Crossover probability & 0.9 \\
Mathematical operators &,,$+- \times, \div$ \\
Mutation probability & 0.01 \\
Tournament size & 4 \\
Operators & 0.5 \\
Variables & 0.5 \\
Number of generations & 1000 \\
\hline
\end{tabular}

complex and long convergence time and often causes overfitting problem beyond specified limit. Moreover, an algorithm run with a large number of generations could lead to a model with minimum error. Several combinations of 
parameters were initiated and the best possible grouping was selected based on the model performance.

2.5. Performance Evaluation. The performance of the developed PSO-MEP model was assessed by measuring various statistical indicators including correlation coefficient $(R)$, root mean squared error (RMSE), Nash-Sutcliffe efficiency (NSE), mean absolute error (MAE), relative root mean squared error (RRMSE), relative squared error (RSE), and performance index $(\rho)$. Moreover, another measure to reduce the model overfitting is to select the best model by minimizing the objective function (OF) as suggested by Gandomi et al. and Azim [34, 69]. The same approach has been applied in this study, and OF is termed as fitness function. The mathematical expressions for the statistical indicators are shown below from equations (2) to (9). The high values of $R$ and NSE and low values of RMSE and MAE indicate better performance. The indicator $R$ quantifies the linear relationship between input and output [27], and $R$ value more than 0.8 signifies excellent correlation among predicted and actual data [70]. However, it alone cannot be considered to judge the efficiency of a model. Despotovic et al. [71] highlighted that a model can be considered excellent if the value of RRMSE is between 0 and 0.10 and good if the values are between 0.11 and 0.20 . The minimum and maximum value of NSE is negative infinity and 1, respectively, with 1 showing the best output. The values of $\rho$ and OF range from 0 to positive infinity with a value near to zero representing a good model. It can be noted that the OF taken into account the effect of RRMSE, $R$, and relative percentage of data in different sets. Hence, low OF value shows superior performance of a model.

$$
\begin{aligned}
\mathrm{RMSE} & =\sqrt{\frac{\sum_{i=1}^{n}\left(P_{i}-M_{i}\right)^{2}}{N}}, \\
\mathrm{NSE} & =1-\frac{\sum_{i=1}^{n}\left(M_{i}-P_{i}\right)^{2}}{\sum_{i=1}^{n}\left(M_{i}-\bar{M}_{i}\right)^{2}}, \\
\mathrm{R} & =\frac{\sum_{i=1}^{n}\left(M_{i}-\bar{M}_{i}\right)\left(P_{i}-\bar{P}_{i}\right)}{\sqrt{\sum_{i=1}^{n}\left(M_{i}-\bar{M}_{i}\right)^{2} \sum_{i=1}^{n}\left(P_{i}-\bar{P}_{i}\right)^{2}}}, \\
\mathrm{MAE} & =\frac{1}{n} \sum_{i=1}^{n}\left|P_{i}-M_{i}\right|, \\
\mathrm{RSE} & =\frac{\sum_{i=1}^{n}\left(P_{i}-M_{i}\right)^{2}}{\sum_{i=1}^{n}\left(\bar{M}_{i}-\bar{M}_{i}\right)^{2}}, \\
\mathrm{RRMSE} & =\frac{1}{|\bar{M}|} \sqrt{\frac{\sum_{i=1}^{n}\left(P_{i}-M_{i}\right)^{2}}{N}}, \\
\rho & =\frac{\operatorname{RRMSE}}{1+R},
\end{aligned}
$$

$$
\mathrm{OF}=\left(\frac{n_{T}-n_{\mathrm{TE}}}{n}\right) \rho_{T}+2\left(\frac{n_{\mathrm{TE}}}{n}\right) \rho_{\mathrm{TE}}
$$

where $n, P_{i}, M_{i}, \bar{P}_{i}$, and $\bar{M}_{i}$ show the number of data points, predicted data, measured data, mean of predicted data, and mean of measured data, respectively. $T$ and TE represent the training and testing datasets, respectively.

\subsection{Hyperparameter Tuning and K-Fold Cross Validation.} Fine-tuning of hyperparameters is a major concern in machine learning-based modeling. Various researchers used different optimization techniques for hyperparameter tuning such as beetle antennae search [22, 72, 73] and grid search method [74]. In our study, particle swarm optimization (PSO) was employed for hyperparameter tuning to improve the accuracy of the model. Firstly, the dataset was divided into $70 \%$ and $30 \%$ for model training and testing, respectively. Then $\mathrm{k}$-fold cross validation was applied to assess the hyperparameter tuning process by PSO. The k-fold method divides the actual data to $k$ subclasses. Moreover, the efficiency of the 10 -fold cross validation method is reported in the literature $[75,76]$. Among all the ten subsets, each subset was used for validation and the same method was repeated for all the remaining subsets. Consequently, the optimized MEP model and the associated optimized hyperparameters were obtained after 10 rounds. After getting the optimum structure of MEP by PSO, the result of training and testing dataset was evaluated employing statistical indicators. Finally, 10-fold cross validation was used again to ensure the generalized capability of PSO-MEP and output was expressed in terms of mean accuracy. Figure 2 shows the hyperparameter tuning process for MEP with the help of PSO for both training and testing.

\section{Experimental Investigation}

3.1. SCBA Processing. The sugarcane bagasse ash (SCBA), resulting from burning of bagasse (as a fuel), was collected from a sugar industry located in Malakand, Pakistan. It has been reported in the literature that the presence of fibrous and unburnt content in raw bagasse ash decreases the pozzolanic activity and also elevates the loss on ignition. Removal of such particles, proper characterization, and grinding up to cement fineness significantly increase its pozzolanic activity $[11,77]$. In our study, the collected SCBA was sieved from \#200 sieve to remove undesirable particles and subsequently grinded to reduce the particle size. Grinding was carried out in ball mill machine with ceramic balls as grinding media. The grinding media to SCBA ratio of 5 by weight was kept constant, and the machine was operated at $100 \mathrm{rpm}$ [78]. Different SCBA samples were obtained at a grinding duration of $15,30,45$, and 60 minutes. Blaine fineness values were determined according to ASTM C204 in order to obtain the effect of grinding on particle size.

The chemical composition of grounded SCBA was evaluated through X-ray fluorescence (XRF). The composition is given in Table 3 . It can be inferred from XRF results 


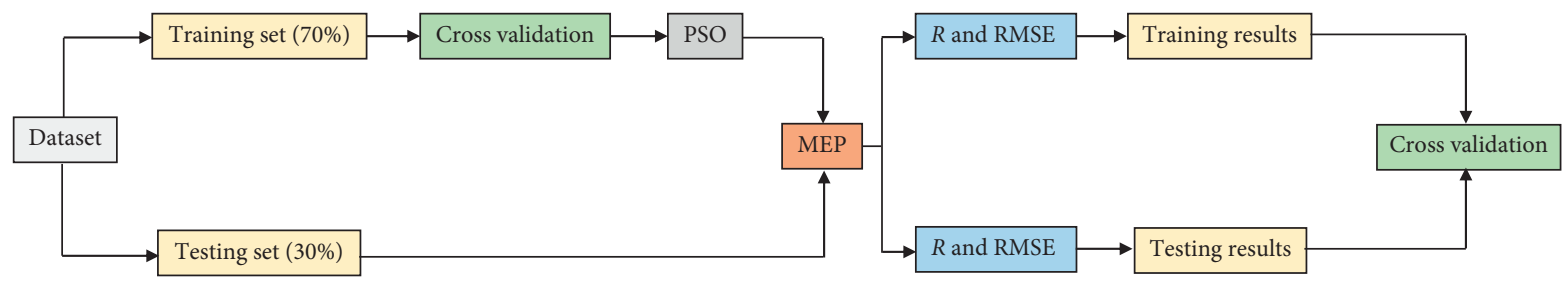

Figure 2: Hyperparameter tuning by PSO.

TABLE 3: XRF results of SCBA.

\begin{tabular}{lc}
\hline Composition & Percentage \\
\hline $\mathrm{SiO}_{2}$ & 66.28 \\
$\mathrm{Al}_{2} \mathrm{O}_{3}$ & 8.36 \\
$\mathrm{Fe}_{2} \mathrm{O}_{3}$ & 1.39 \\
$\mathrm{CaO}$ & 9.06 \\
$\mathrm{MgO}$ & 5.56 \\
$\mathrm{P}_{2} \mathrm{O}_{5}$ & 2.46 \\
$\mathrm{~K}_{2} \mathrm{O}$ & 3.52 \\
$\mathrm{Na}_{2} \mathrm{O}$ & 1.30 \\
$\mathrm{TiO}_{2}$ & 0.19 \\
$\mathrm{MnO}$ & 0.02 \\
$\mathrm{LOI}$ & 1.67 \\
Moisture content & 1.15 \\
\hline
\end{tabular}

that the quantity of silica, alumina, and iron oxide is above $70 \%$, meeting the chemical requirement of a pozzolan according to ASTM C618-05 standard.

Scanning electron micrographs of SCBA are shown in Figure 3. Images were taken at different magnification ranging from $\mathrm{X} 500$ to $\mathrm{X} 5000$. In the micrographs, the heterogeneous nature of SCBA is prominent. The SCBA exhibited various shapes such as elongated, needle, flat, oval, and irregular. According to available literature [79], the irregular shape particles are mainly rich in silica. The size of needle and oval shape particles is about $50 \mu \mathrm{m}$. Furthermore, voids over the surface ranging from $5 \mu \mathrm{m}$ to $10 \mu \mathrm{m}$ are visible in the form of black spots. Overall, the observed size of different particles ranges from $5 \mu \mathrm{m}$ to $50 \mu \mathrm{m}$.

\subsection{Mix Proportions and Properties of SCBA Concrete.} Experimental testing of SCBA concrete was conducted to check the performance of the model required for validation purpose. Concrete specimens were casted at room temperature of $25^{\circ} \mathrm{C}$, and comparison of fresh and hardened properties was made between concrete made with bagasse ash (BC) and control specimens (CM). Different dosages of SCBA, i.e., 0-40\%, were incorporated in concrete as cement replacement. The desired target strength was formulated based on published data as adamant variation was observed. The detailed mix design with the formulation is depicted in Table 4

For the validation of the PSO-MEP model, concrete specimens, i.e., cylinders and 4 " $\times 4$ " $\times 20^{\prime \prime}$ beams, were prepared with different proportions of SCBA and tested for compressive strength (CS), splitting tensile strength (ST), and flexural strength (FS), respectively, at the curing age of 28 days. ASTM standards C39, C496, and C293 were, respectively, followed for compressive, splitting tensile, and flexural strength of the $\mathrm{CM}$ and $\mathrm{BC}$.

\section{Results and Discussion}

4.1. Mechanical Properties of SCBA Concrete. The results of mechanical properties, i.e., compressive strength (CS), splitting tensile strength (ST), and flexural strength (FS), of SCBA concrete were determined in laboratory by casting concrete cylinders and beams with varying proportions of SCBA ( $0 \%$ to $40 \%$ ), as presented in Table 5 . It can be observed that strength increased up to $10 \%$ SCBA and then consistently decreased at higher SCBA level. The maximum strength gained is at $10 \%$ replacement. The strength gain at $10 \%$ SCBA may be related to the pozzolanic reaction resulting in additional calcium silicate hydrate (CSH). For higher replacement level, the decrease in strength was found to be $6.5 \%, 17.3 \%$, and $30.3 \%$ for $20 \mathrm{BC}, 30 \mathrm{BC}$, and $40 \mathrm{BC}$, respectively. This decrease in strength may be attributed to unavailability of the adequate amount of calcium hydroxide.

Similar results were observed for splitting tensile strength and flexural strength as illustrated in Table 5. For $10 \%$ and $20 \%$ replacement of SCBA, the increase in tensile strength as compared to control concrete was $25.3 \%$ and $15.8 \%$, respectively. This shows that the maximum tensile strength was attained at $10 \%$ addition of SCBA as cement replacement. For $30 \%$ and $40 \%$ SCBA replacement level, the tensile strength decreased by $7.9 \%$ and $23.8 \%$, respectively, as compared to CM. For the case of flexural strength, the maximum strength was also achieved at $10 \%$ SCBA. The flexural strength at higher replacement level $(20 \%, 30 \%$, and $40 \%$ SCBA) reduced by $15.5 \%, 28.8 \%$, and $42.5 \%$, respectively. According to available literature, the increased tensile and flexural strength at $10 \%$ SCBA may be due to the microfibrous nature of SCBA, which is related with CSH formation, and also due to the formation of aluminates, resulting in needle-like structure $[80,81]$. The interlocking of these needles takes place between hydrated paste and may directly enhance the tensile and flexural strength. In short, the enhanced properties may be due to formation of more hydrated products, less porous structure of concrete made with SCBA, and the enhanced interfacial transition zone (ITZ) $[80,82,83]$.

4.2. Formulation of Mechanical Properties with PSO-MEP. The results obtained from PSO-MEP for compressive strength (CS), splitting tensile strength (ST), and flexural strength (FS) are interpreted to get the empirical mathematical expressions for the prediction of aforementioned 

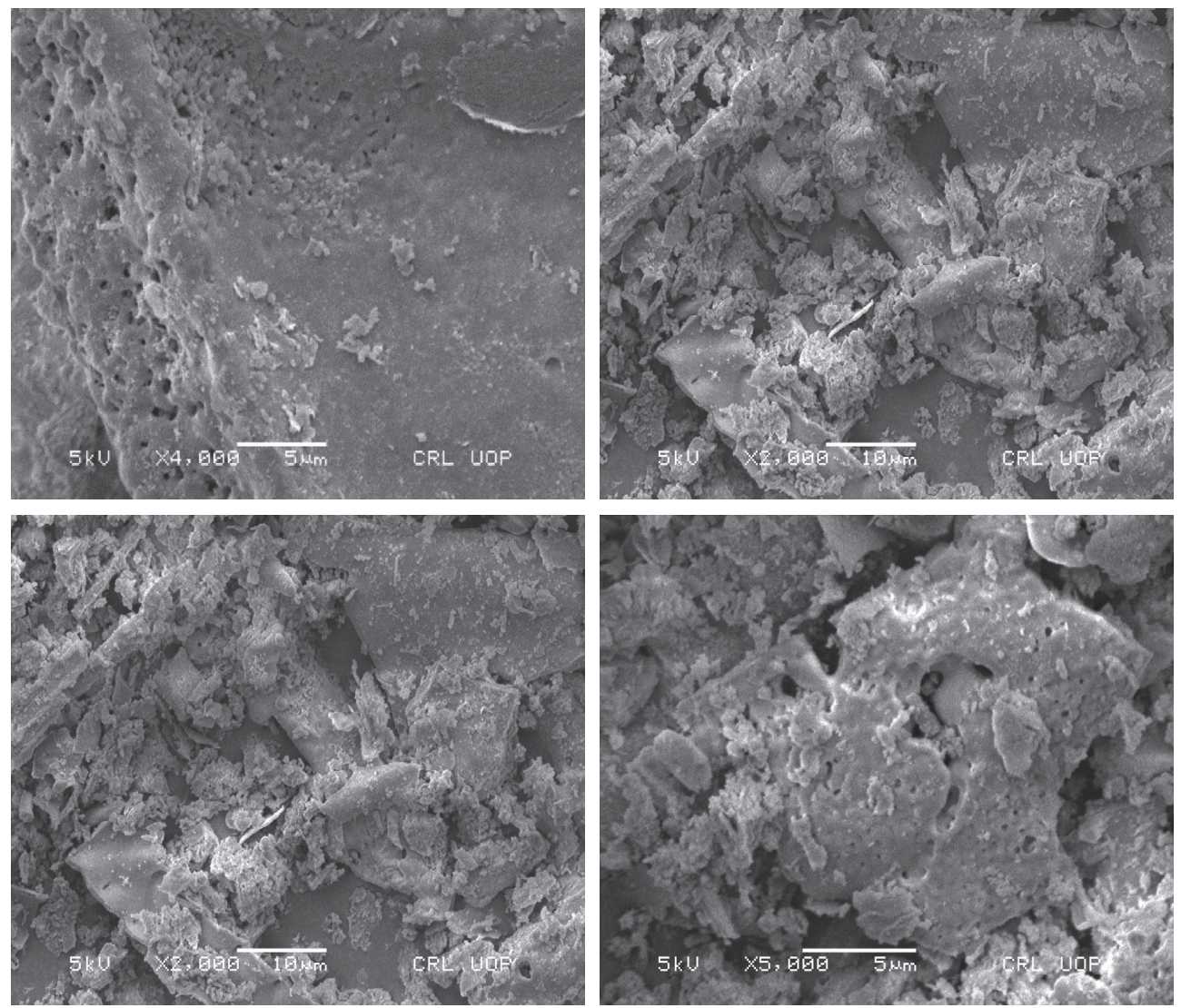

Figure 3: SEM images of SCBA at different magnifications.

Table 4: Mix Proportions of the concrete mix.

\begin{tabular}{lcccccc}
\hline Mix design & Cement $\left(\mathrm{kg} / \mathrm{m}^{3}\right)$ & Coarse aggregate $\left(\mathrm{kg} / \mathrm{m}^{3}\right)$ & SCBA $\left(\mathrm{kg} / \mathrm{m}^{3}\right)$ & W/C & Fine aggregate $\left(\mathrm{kg} / \mathrm{m}^{3}\right)$ & Water $\left(\mathrm{kg} / \mathrm{m}^{3}\right)$ \\
\hline 0BC $(\mathrm{CM})$ & 366 & 1013.5 & 0 & 0.5 & 742.3 & 183 \\
10BC & 329.4 & 1013.5 & 36.6 & 0.5 & 742.3 & 183 \\
20BC & 292.8 & 1013.5 & 73.2 & 0.5 & 742.3 & 183 \\
30BC & 256.2 & 1013.5 & 109.8 & 0.5 & 742.3 & 183 \\
40BC & 219.6 & 1013.5 & 146.4 & 0.5 & 742.3 & 183 \\
\hline
\end{tabular}

properties based on five input variables. The derived equations are shown as equations (10), (11), and (12) for CS, ST, and FS, respectively. A comparative graph of experimental and predicted CS is presented in Figure 4 for training, testing, and validation. The expressions for regression lines are also shown. For an ideal situation, it is known that the slope of the line should be nearly equal to 1 . It can be deduced from Figure 4 that the developed PSOMEP model considered the effect of input variables and retains a strong correlation between experimental and predicted data as evident from the slope, i.e., 0.8951, 0.9315, and 0.9014 for training, testing, and validation, respectively.

$$
\begin{aligned}
& \mathrm{CS}(\mathrm{MPa})=\left(1.1 x_{1}+1.1 x_{2}\right)+\left(\frac{8 x_{0}^{2} \times x_{4}}{x_{3}-x_{4}}\right)\left(16 x_{0}^{3}\left(1.1 x_{1}+1.1 x_{2}\right)+\frac{4\left(5 x_{1}-x_{3}\right)}{1.1 x_{1}+1.1 x_{2}}\right)^{2}, \\
& \mathrm{ST}(\mathrm{MPa})=\left(x_{0}+\frac{x_{0}^{2}}{x_{0}-0.375}\right)-\left(\frac{x_{0}-0.375}{\left(x_{0}-x_{1}\right)+\left(x_{0} / x_{0}-0.375\right)}\right)+\frac{\left(x_{0}-0.375\right)^{2}}{\left(x_{0}^{2}-0.375\right)^{2}}-\left(\frac{x_{0} \times x_{1}^{2}}{x_{2}}\right)+\frac{x_{0}^{2} \times x_{3}}{x_{4}-0.375}, \\
& \mathrm{FS}(\mathrm{MPa})=\left(\frac{2 x_{3} x_{0}}{x_{4}+\left(3 x_{2}+0.97\right)^{2}\left(2 x_{1}-89 x_{0}\right)}\right)+\left(\frac{2 x_{0}}{\left(\left(x_{1}-89 x_{0}\right) /\left(100 x_{0}-48.5\right)\right)}\right),
\end{aligned}
$$


TABLE 5: Results of laboratory-derived mechanical properties of SCBA concrete.

\begin{tabular}{|c|c|c|c|c|c|}
\hline \multirow{2}{*}{ Mix } & \multicolumn{5}{|c|}{ Compressive strength $(\mathrm{MPa})$} \\
\hline & OBC & $10 \mathrm{BC}$ & $20 \mathrm{BC}$ & $30 \mathrm{BC}$ & $40 \mathrm{BC}$ \\
\hline Sample 1 & 23.5 & 23.9 & 21.5 & 18.5 & 16.7 \\
\hline Sample 2 & 22.7 & 23.6 & 21.6 & 19.6 & 15.6 \\
\hline Sample 3 & 22.9 & 23.7 & 21.2 & 19.1 & 16.4 \\
\hline Sample 4 & 23.4 & 24.2 & 22.3 & 19.5 & 15.7 \\
\hline Average & 23.1 & 23.8 & 21.6 & 19.1 & 16.1 \\
\hline \multicolumn{6}{|c|}{ Splitting tensile strength (MPa) } \\
\hline Sample 1 & 6.3 & 7.9 & 7.2 & 6.7 & 5.3 \\
\hline Sample 2 & 6.2 & 7.8 & 7.3 & 5.6 & 4.7 \\
\hline Sample 3 & 6.2 & 8.1 & 7.5 & 5.3 & 4.4 \\
\hline Sample 4 & 6.7 & 8.1 & 7.5 & 5.8 & 4.9 \\
\hline Average & 6.3 & 7.9 & 7.3 & 5.8 & 4.8 \\
\hline \multicolumn{6}{|c|}{ Flexural strength $(\mathrm{MPa})$} \\
\hline Sample 1 & 4.7 & 5.1 & 3.9 & 3.1 & 2.8 \\
\hline Sample 2 & 4.3 & 5.1 & 3.8 & 3.3 & 2.6 \\
\hline Sample 3 & 4.6 & 5.2 & 3.8 & 3.3 & 2.6 \\
\hline Sample 4 & 4.6 & 5.3 & 3.7 & 3.2 & 2.5 \\
\hline Average & 4.5 & 5.1 & 3.8 & 3.2 & 2.6 \\
\hline
\end{tabular}

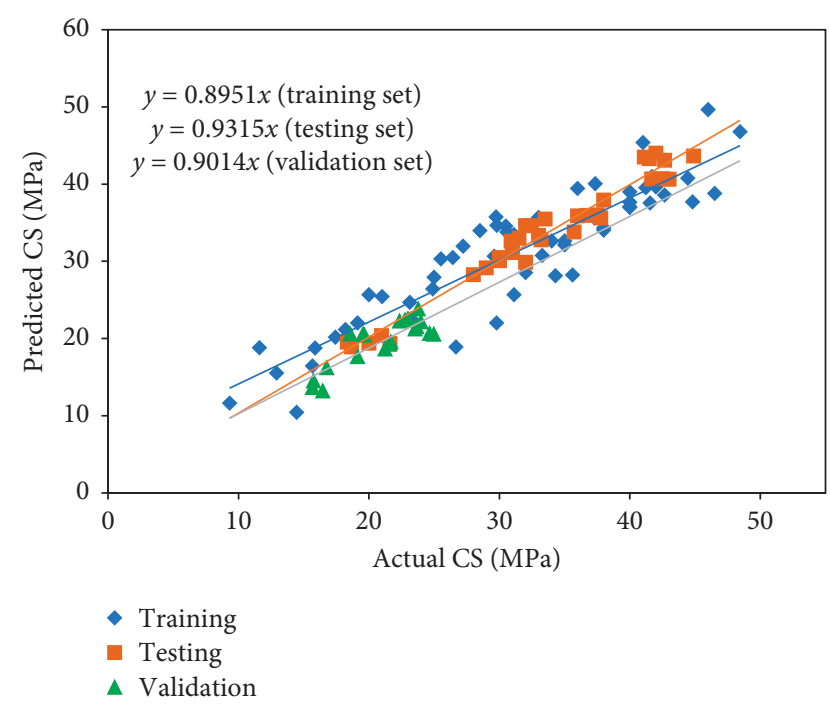

FIgURE 4: Comparison of actual and predicted CS.

where

$$
\begin{aligned}
& x_{0}=\frac{w}{c}, \\
& x_{1}=\mathrm{SCBA} \% \\
& x_{2}=\mathrm{CC}, \\
& x_{3}=\mathrm{FA}, \\
& x_{4}=\mathrm{CA} .
\end{aligned}
$$

A similar comparison has been drawn for the tensile strength (ST) output as shown in Figure 5. It can be seen that the model exhibited an excellent correlation among experimental and predicted data to estimate ST. The respective slopes of the regression line are close to ideal fit, i.e., 0.9351,
0.8903 , and 0.9273 for training, testing, and validation. Similar to CS, the model for ST performs exceptionally well on training dataset revealing that the issue of overfitting by the model has been reduced to a larger extent. Moreover, the performance and accuracy of a model depend on the number of data points incorporated in the model [84]. In this study, 110 data points have been selected to model ST; therefore, an accurate model with minimum error has been achieved.

The PSO-MEP model results for flexural strength (FS) are graphically presented in Figure 6. During model training, testing, and validation, the slope of the regression line was observed to be $0.9494,0.9026$, and 0.9332 . Compared with the models for CS and ST, an excellent estimate is observed for experimental and predicted data point as illustrated in Figure 6 . The model performs exceptionally well for training and testing data.

4.3. Model Evaluation by Statistical Measures. The reliability of a model depends on the amount of data used for model development. The literature survey recommended that the ratio of number of data points to the number of input variables for both training and testing should be greater than 5 [85]. For model training, the aforementioned ratio is 11.8 , 13.8, and 8.2 for CS, ST, and FS, respectively. For model testing, the values are 6.2, 6.6, and 5.7 for CS, ST, and FS, respectively. The performance of the developed models was evaluated by various statistical criteria such as RMSE, NSE, RSE, RRMSE, OF, $\rho$, MAE, and $R$. The values of these indicators for CS, ST, and FS are given in Table 6 for training, testing, and validation. It can be observed from Table 6 that models exhibit a strong correlation as evident by the $R$ value which is $0.91,0.90$, and 0.91 for training and $0.94,0.92$, and 0.91 for testing of CS, ST, and FS, respectively. The maximum and minimum values of NSE are 0.89 and 0.87 for CS, 0.91 and 0.85 for ST, and 0.86 and 0.87 for FS models, respectively. The values of RMSE and MAE are considerably 


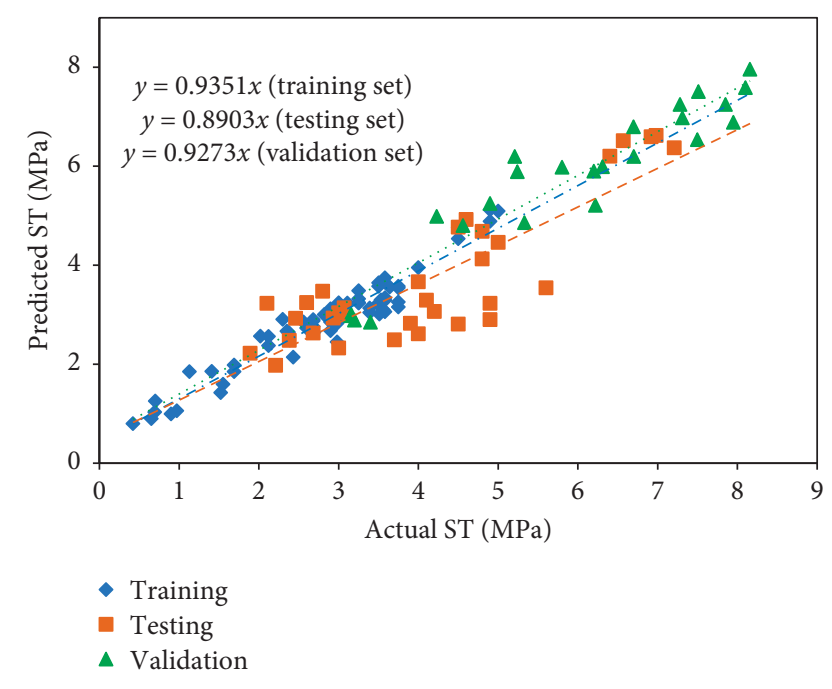

FIgURE 5: Comparison of actual and predicted ST.

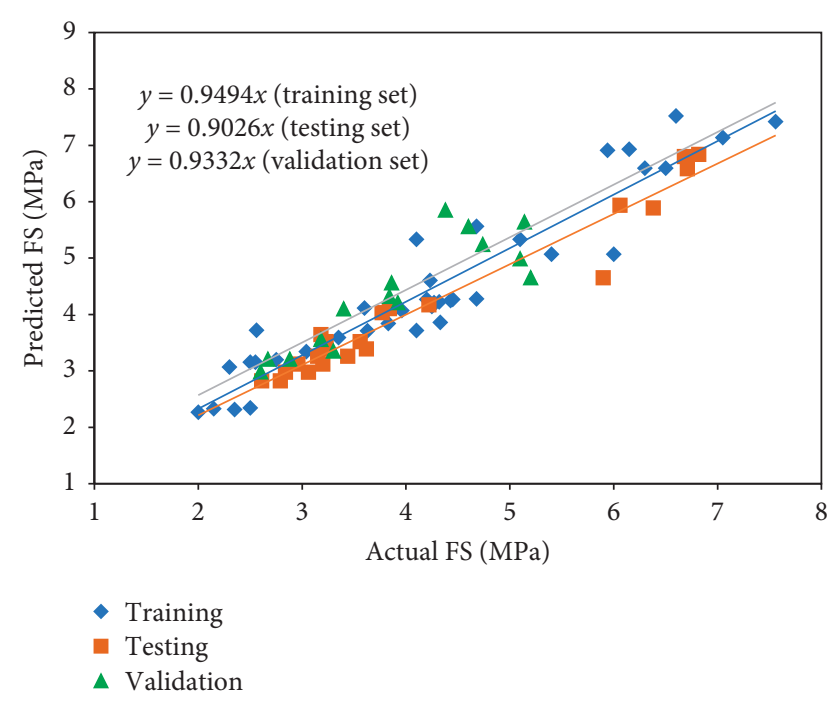

Figure 6: Comparison of actual and predicted FS.

low for the three datasets which highlighted the generalized capability and high accuracy of the models. Based on RMSE, the model for ST can be categorized as excellent, as the values for all the three datasets are 2.43, 2.65, and 3.25, respectively. It can be deduced from results that for all models, MAE lies in the good range from 1.45 to 3.98. Furthermore, the OF values for CS, ST and FS are 0.036, 0.031, and 0.052, respectively. All these values are close to zero, indicating the accurate performance and further validating that the overfitting problem has been suitably addressed by the models. For all the developed models, the RRMSE ranged from 0.04 to 0.16 , thus highlighting the accuracy of the model in predicting the mechanical properties of SCBA concrete. In order to infer the absolute error, the data points are plotted in Figure 7 showing the error among actual and model simulated data. The mean absolute error for CS, ST, and FS is $2.87,0.405$, and 0.675 , respectively. The minimum and maximum absolute errors are 0.1 and 7.76 for CS, 0.08 and 2.15 for ST, and 0.075 and 1.95 for FS, respectively. It is worth mentioning that almost $80 \%$ of results for CS, ST, and FS have error less than 3, 0.5, and 0.6, respectively.

The criteria for external validation of the models are given in Table 7 . It has been suggested that regression line slope, i.e., $k$ and $k^{\prime}$, passing through the origin should be nearly equal to 1 [86]. Roy and Roy [87] reported that criteria for external predictability of a model are satisfied when the indicator $R_{m}$ is greater than 0.5 . It can be observed from Table 7 that all the three models (CS, ST, and FS) satisfy the conditions for external predictability.

4.4. Model Cross Validation Results. The 10-fold cross validation was applied to evaluate the CS, ST, and FS models, and the results are graphically shown in Figures 8 and 9 for $R$ and RMSE, respectively. A variation in the results can be observed at individual level as depicted in the figure. However, it demonstrated a good mean accuracy. The average $R$ value obtained for CS, ST, and FS is $0.85,0.89$, and 0.85 , respectively. In all the 10 -fold cross validations, the maximum and minimum $R$ values of 0.72 and 0.91 , respectively, were achieved by ST. Similarly, the mean RMSE values of 4.54, 3.89, and 4.78 were accomplished by CS, ST, and FS, respectively. For individual subset, the lowest RMSE, i.e., 1.86, was also attained by ST. Overall, the results from 10 -fold cross validation shows the accurate performance, generalized capability, and robustness of the PSO-MEP models.

4.5. Variable Importance and Parametric Analysis. Variable importance is a process to find out the most influencing input variables affecting the targeted output. The most sensitive input parameters and their relative contribution to output were determined, and the results are illustrated in Figure 10. The result shows that cement content is the most important variable contributing 55\% to mechanical properties of SCBA concrete. Similarly, water-cement ratio and amount of coarse aggregate turned out to be important variables with $17.15 \%$ and $16.97 \%$ contribution to the output. The result further reveals that quantity of fine aggregate is the least important parameter affecting the mechanical properties of SCBA concrete.

Parametric analysis was performed to assess the variation of the model output with every single input variable. This process is recommended in research studies to determine the effect of all the physical phenomena and inputs. In this method, all the variables were kept constant at their mean values and the variation of the model output is plotted with a single input variable. The same procedure was applied for the individual input parameter. Figure 11 shows the parametric analysis results for the developed CS model only as similar patterns were obtained for other mechanical properties (ST and FS). Therefore, parametric study results are discussed in detail for CS in the following.

It is a known fact that an increase in water-cement ratio decreases the strength of concrete $[84,88]$. It can be seen form Figure 11(a) that an increase in W/C resulted in a consistent decrease in compressive strength. The effect of SCBA\% on the mechanical properties of SCBA concrete depends on physical and chemical composition and 
TABLE 6: Statistics for the training, testing, and validation dataset of the models.

\begin{tabular}{lccccccccc}
\hline Models & Dataset & NSE & $R$ & RMSE & MAE & RSE & RRMSE & $\rho$ \\
\hline \multirow{3}{*}{ CS } & Training & 0.87 & 0.91 & 3.47 & 2.96 & 0.16 & 0.04 & 0.020 & OF \\
& Testing & 0.89 & 0.94 & 2.98 & 2.98 & 0.12 & 0.09 & 0.046 & 0.036 \\
& Validation & 0.89 & 0.93 & 2.87 & 1.67 & 0.15 & 0.04 & 0.020 \\
\multirow{3}{*}{ ST } & Training & 0.85 & 0.90 & 2.43 & 3.67 & 0.23 & 0.09 & 0.047 \\
& Testing & 0.91 & 0.92 & 2.65 & 3.69 & 0.26 & 0.12 & 0.062 & 0.031 \\
& Validation & 0.90 & 0.92 & 3.25 & 3.98 & 0.31 & 0.10 & 0.052 \\
\multirow{2}{*}{ FS } & Training & 0.86 & 0.91 & 3.92 & 1.87 & 0.29 & 0.13 & 0.068 \\
& Testing & 0.87 & 0.91 & 3.34 & 1.45 & 0.28 & 0.15 & 0.078 & 0.052 \\
& Validation & 0.86 & 0.93 & 3.67 & 2.87 & 0.19 & 0.16 & 0.079 \\
\hline
\end{tabular}

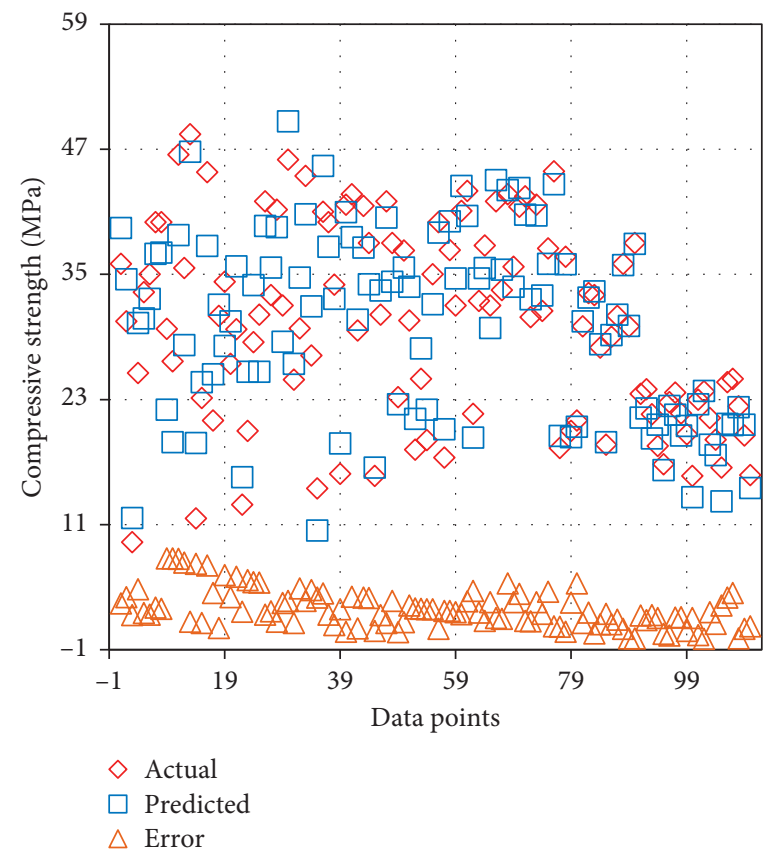

(a)

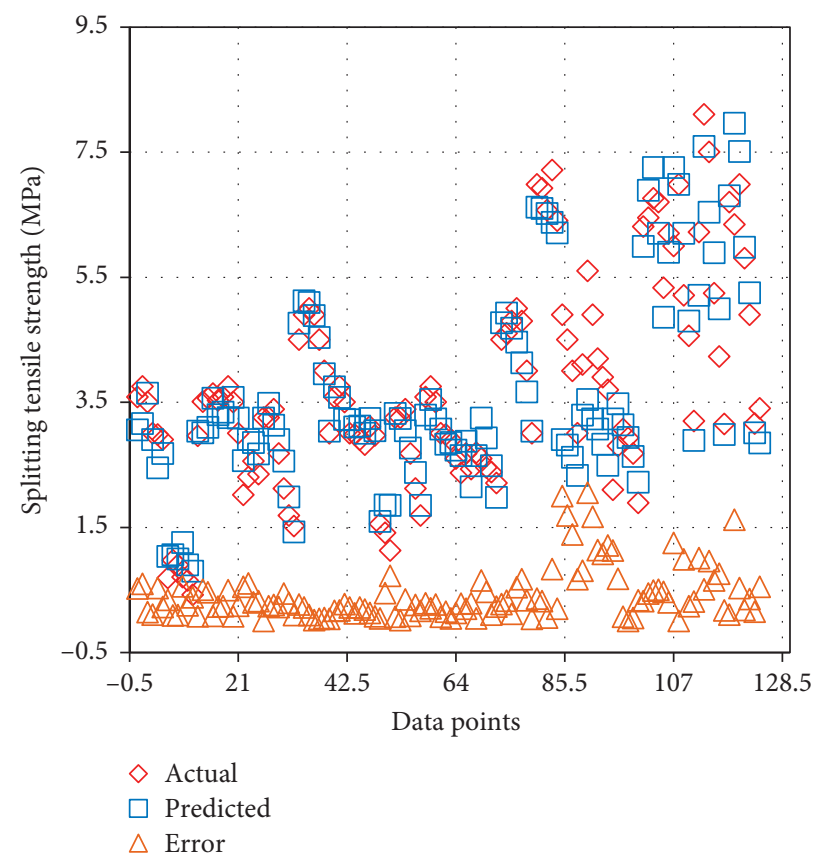

(b)

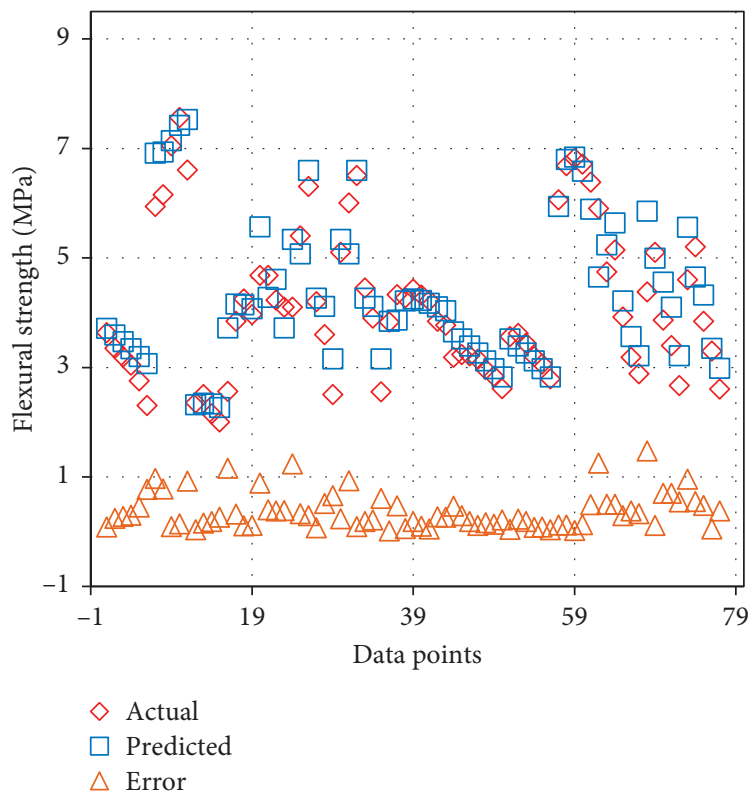

(c)

FIGURE 7: Description of the error among the actual and predicted data: (a) CS; (b) ST; (c) FS. 
TABLE 7: Statistical indicators of verified models for external predictability.

\begin{tabular}{lcccccc}
\hline S.No. & Equation & Condition & CS & ST & FS & Suggested by \\
\hline 1. & $R=\frac{\sum_{i=1}^{n}\left(M_{i}-\bar{M}_{i}\right)\left(P_{i}-\bar{P}_{i}\right)}{\sqrt{\sum_{i=1}^{n}\left(M_{i}-\overline{M_{i}}\right)^{2} \sum_{i=1}^{n}\left(P_{i}-\bar{P}_{i}\right)^{2}}}$ & $R>0.8$ & 0.92 & 0.92 & 0.91 & Frank and Todeschini [85] \\
2. & $k=\frac{\sum_{i=1}^{n}\left(M_{i}-P_{i}\right)}{M_{i}^{2}}$ & $0.85<k<1.15$ & 1.00 & 0.99 & 1.01 & Golbraikh and Tropsha [86] \\
3. & $k^{\prime}=\frac{\sum_{i=1}^{n}\left(M_{i}-P_{i}\right)}{P_{i}^{2}}$ & $0.85<k^{\prime \prime}<1.15$ & 0.98 & 0.98 & 1.05 & Golbraikh and Tropsha [86] \\
& $R_{m}=R^{2} \times\left(1-\sqrt{\left|R^{2}-R_{0}^{2}\right|}\right.$ & $R_{\mathrm{m}}>0.5$ & 0.67 & 0.71 & 0.64 & Roy and Roy [87] \\
4. & $R_{0}^{2}=\frac{\sum_{i=1}^{n}\left(P_{i}-M_{i}^{0}\right)^{2}}{\sum_{i=1}^{n}\left(P_{i}-\overline{P_{i}^{0}}\right)^{2}}, \quad M_{i}^{0}=k \times P_{i}$ & $R_{0}^{2} \cong 1$ & 0.98 & 0.98 & 0.97 &
\end{tabular}

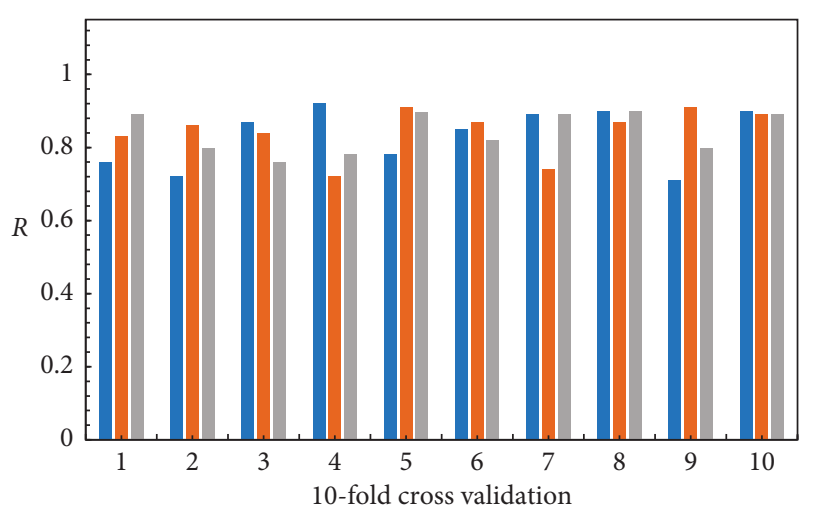

- CS

- ST

- FS

FIgURE 8: Cross validation results of CS, ST, and FS models based on $R$.

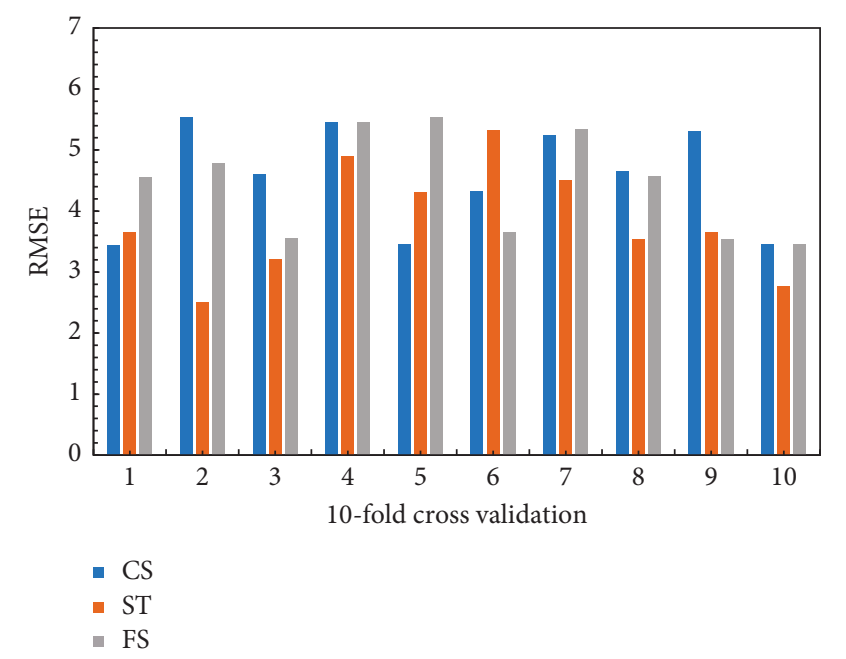

FIGURE 9: Cross validation results of CS, ST, and FS models based on RMSE.

replacement percentage of SCBA [11]. It can observed in Figure 11(b) that the compressive strength of SCBA concrete increased up to a certain level and then decreased with

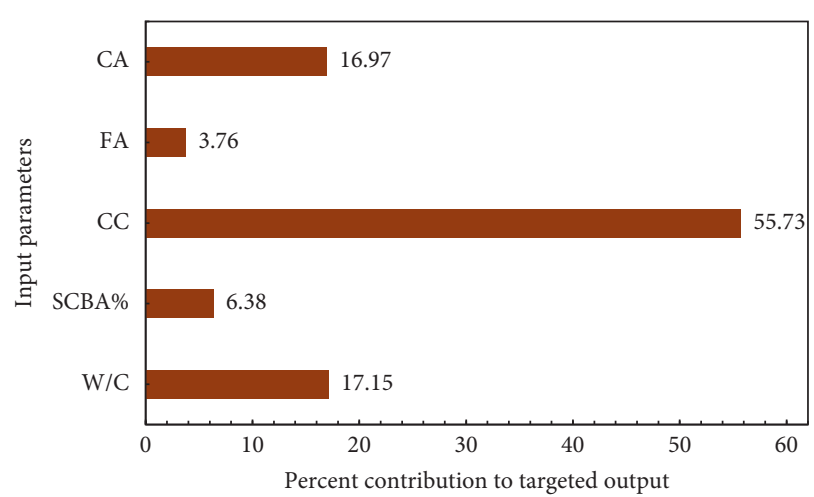

FIGURE 10: Importance of input variables on the targeted output.

increase in the level SCBA\%. It can be deduced from the figure that maximum strength has been attained at $10 \%$ SCBA replacement. A similar trend was also observed for experimental testing of SCBA concrete as described in Section 4.1. Hence, the results of parametric analysis are in close agreement with laboratory testing where maximum strength was achieved at 10\% SCBA. Similar findings were reported in [9-11] which showed that 10\% SCBA replacement attained higher strength.

Cement is the principal cementitious material in concrete, and the increase in the cement content enhances the mechanical properties of concrete. A similar trend can also be seen in Figure 11(c) where the compressive strength linearly increased with increase in cement content. The higher cement content produces more calcium silicate hydrate (CSH) which forms a dense structure, thereby increasing the compressive strength. Figures 11(d) and 11(e) illustrate the variation of compressive strength with fine and coarse aggregate content, respectively. Both figures demonstrated that CS decreased with the increase in FA and CA content. The aggregates are inert materials and are used to provide volume stability to concrete. The quantity of aggregates affects the mechanical properties of concrete. However, keeping all the quantities constant in a mix, the strength of concrete decreases with increase in the quantity of aggregate. Similar results were also observed in the current study. 


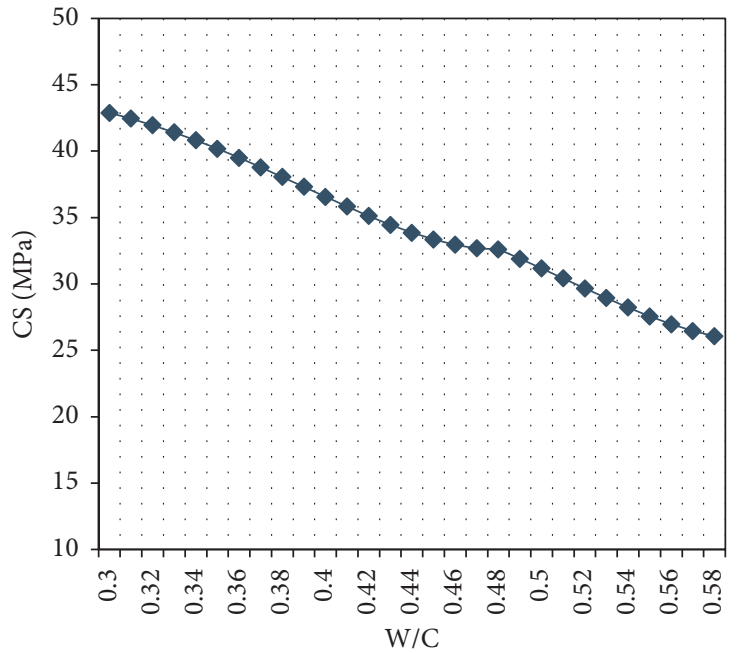

(a)

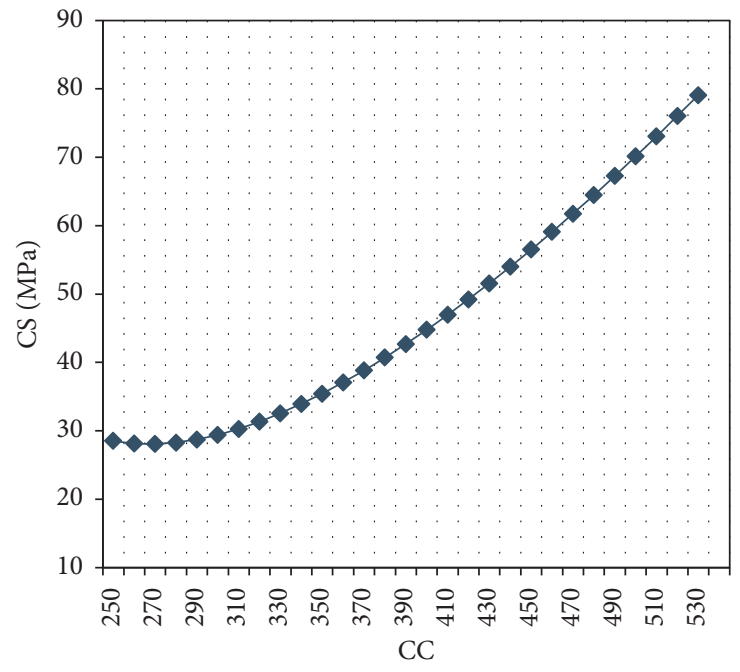

(c)

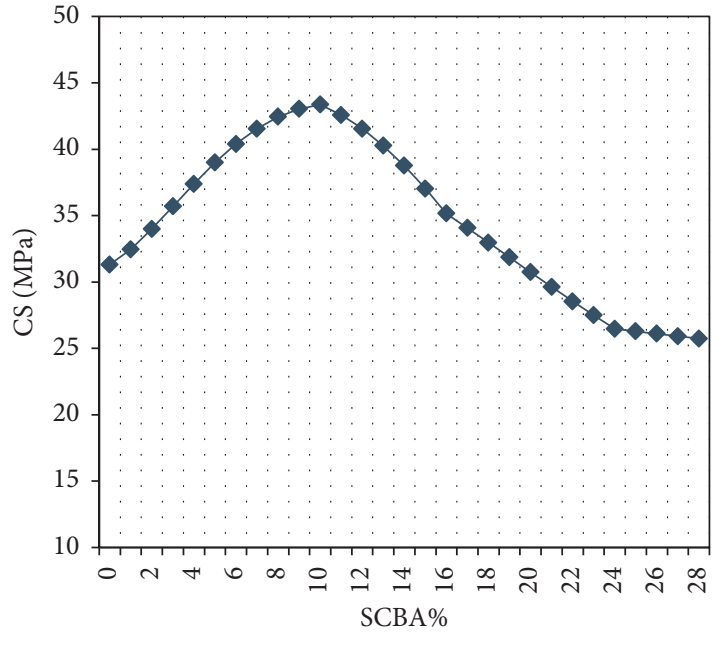

(b)

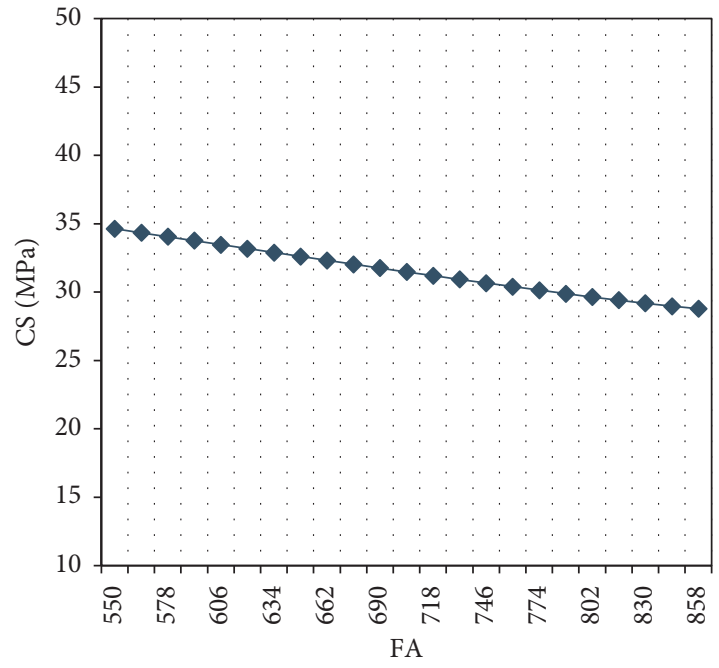

(d)

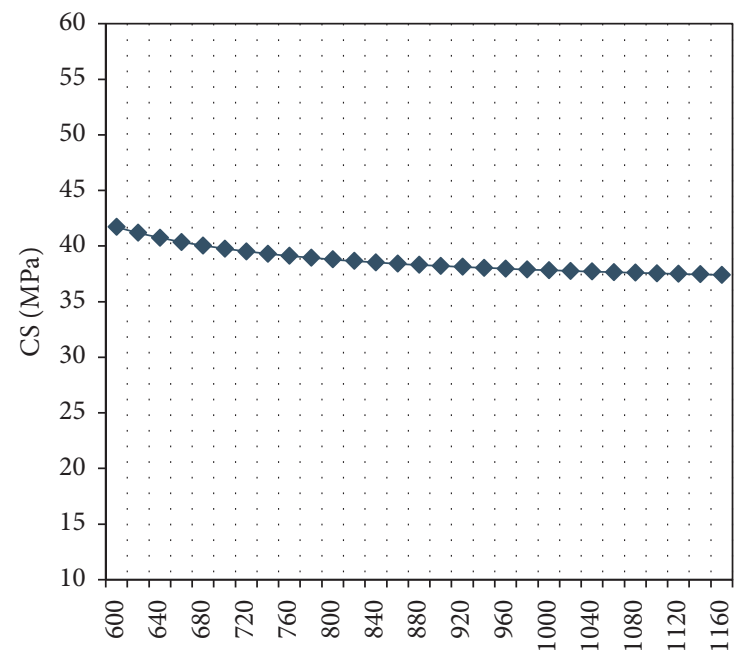

CA

(e)

Figure 11: Parametric analysis results for (a) W/C, (b) SCBA\%, (c) CC, (d) FA, and (e) CA. 
From the aforementioned discussion, it can be concluded that the developed PSO-MEP model has successfully incorporated the effect of all input variables, specifically the complex physical behavior of SCBA, thus making it more suitable for estimation of complex problems.

\section{Conclusion}

This study adopted the two-fold objective. Firstly, the compressive strength, splitting tensile strength, and flexural strength of SCBA concrete were modeled by utilizing multiexpression programming (MEP). The particle swarm optimization (PSO) was employed to tune the hyperparameter of the model. The proposed model was developed and formulated based on extensive literature data. Secondly, sugarcane bagasse ash (SCBA) was characterized, optimized, and used in different proportions $(10 \%, 20 \%, 30 \%$, and $40 \%)$ as a partial replacement with cement. SCBA concrete specimens were prepared and tested for mechanical properties, and the results were used for model validation. The performance and accuracy of the final models were evaluated with the help of statistical indicators, i.e., RMSE, NSE, RSE, RRMSE, OF, $\rho$, MAE, and R. The results obtained from the developed models exhibited an excellent correlation with the experimental data with $R$ value above 0.9, MAE and RMSE below 5, and OF values close to zero for CS, ST, and FS models. The developed PSO-MEP models also satisfied the criteria for external validation available in the literature. The variable importance and parametric analysis revealed that the developed model has taken into account the effect of all the inputs. The final outcome of the model was also cross verified with the 10-fold validation; the results ensured that the models produced generalized outcome, and the overfitting issue has also been addressed. It is obvious from the current study that utilization of different wastes is indispensable for sustainability viewpoint and machine learning models play a crucial role in its success.

\section{Data Availability}

The data used in this study were collected from the published literature and are available from the corresponding author upon request.

\section{Conflicts of Interest}

The authors declare that they have no conflicts of interest.

\section{References}

[1] H. Du and S. D. Pang, "Value-added utilization of marine clay as cement replacement for sustainable concrete production," Journal of Cleaner Production, vol. 198, pp. 867-873, 2018.

[2] Z. He, X. Zhu, J. Wang, M. Mu, and Y. Wang, "Comparison of $\mathrm{CO} 2$ emissions from OPC and recycled cement production," Construction and Building Materials, vol. 211, pp. 965-973, 2019.

[3] L.-X. Mao, Z. Hu, J. Xia et al., "Multi-phase modelling of electrochemical rehabilitation for ASR and chloride affected concrete composites," Composite Structures, vol. 207, pp. 176-189, 2019.
[4] M. F. Iqbal, Q.-f. Liu, I. Azim et al., "Prediction of mechanical properties of green concrete incorporating waste foundry sand based on gene expression programming," Journal of Hazardous Materials, vol. 384, Article ID 121322, 2020.

[5] W. A. Pippo and C. A. Luengo, "Sugarcane energy use: accounting of feedstock energy considering current agro-industrial trends and their feasibility," International Journal of Energy and Environmental Engineering, vol. 4, no. 1, p. 10, 2013.

[6] G. C. Cordeiro, D. C. T. F. Romildo, M. F. Eduardo et al., "Influence of mechanical grinding on the pozzolanic activity of residual sugarcane bagasse ash," in Proceedings of International RILEM Conference on the Use of Recycled Materials in Building and Structures, Barcelona, Spain, January 2004.

[7] K. Pedersen, A. Jensen, M. Skjothrasmussen, and K. Damjohansen, "A review of the interference of carbon containing fly ash with air entrainment in concrete," Progress in Energy and Combustion Science, vol. 34, no. 2, pp. 135-154, 2008.

[8] N. Chusilp, C. Jaturapitakkul, and K. Kiattikomol, "Utilization of bagasse ash as a pozzolanic material in concrete," Construction and Building Materials, vol. 23, no. 11, pp. 3352-3358, 2009.

[9] M. H. R. Sobuz, "Properties of concrete by using bagasse ash and recycle aggregate," Concrete Research Letters, vol. 5, 2014.

[10] P. Jagadesh, A. Ramachandramurthy, and R. Murugesan, "Evaluation of mechanical properties of sugar cane bagasse ash concrete," Construction and Building Materials, vol. 176, pp. 608-617, 2018.

[11] A. Bahurudeen, D. Kanraj, V. Gokul Dev, and M. Santhanam, "Performance evaluation of sugarcane bagasse ash blended cement in concrete," Cement and Concrete Composites, vol. 59, pp. 77-88, 2015.

[12] A. Bahurudeen and M. Santhanam, "Performance evaluation of sugarcane bagasse ash-based cement for durable concrete," in Proceedings of the International Conference on the Durability of Concrete Structures, Dunbeath, Caithness, UK, July 2014.

[13] A. Bahurudeen, S. Manu, W. Kaiser et al., "Assesment of pozzolanic performance of sugarcane bagasse ash," Journal of Materials in Civil Engineering, vol. 28, no. 2, Article ID 04015095, 2016.

[14] A. Rerkpiboon, W. Tangchirapat, and C. Jaturapitakkul, "Strength, chloride resistance, and expansion of concretes containing ground bagasse ash," Construction and Building Materials, vol. 101, pp. 983-989, 2015.

[15] M. I. Khan, "Predicting properties of high performance concrete containing composite cementitious materials using artificial neural networks," Automation in Construction, vol. 22, pp. 516-524, 2012.

[16] A. T. A. Dantas, M. Batista Leite, and K. de Jesus Nagahama, "Prediction of compressive strength of concrete containing construction and demolition waste using artificial neural networks," Construction and Building Materials, vol. 38, pp. 717-722, 2013.

[17] E. M. Golafshani, A. Behnood, and M. Arashpour, "Predicting the compressive strength of normal and high-performance concretes using ANN and ANFIS hybridized with grey wolf optimizer," Construction and Building Materials, vol. 232, Article ID 117266, 2020.

[18] R. Parichatprecha and P. Nimityongskul, "Analysis of durability of high performance concrete using artificial neural networks," Construction and Building Materials, vol. 23, no. 2, pp. 910-917, 2009. 
[19] J. Sun, J. Zhang, Y. Gu, Y. Huang, Y. Sun, and G. Ma, "Prediction of permeability and unconfined compressive strength of pervious concrete using evolved support vector regression," Construction and Building Materials, vol. 207, pp. 440-449, 2019.

[20] J. Zhang, D. Li, and Y. Wang, "Toward intelligent construction: prediction of mechanical properties of manufactured-sand concrete using tree-based models," Journal of Cleaner Production, vol. 258, Article ID 120665, 2020.

[21] Y. Sun, G. Li, J. Zhang et al., "Prediction of the strength of rubberized concrete by an evolved random forest model," Advances in Civil Engineering, Article ID 5198583, 7 pages, 2019.

[22] J. Huang, T. Duan, Z. Yi et al., "Predicting the permeability of pervious concrete based on the beetle antennae search algorithm and random forest model," Advances in Civil Engineering, vol. 2020, Article ID 8863181, 11 pages, 2020.

[23] A. Ashteyat, Y. T. Obaidat, Y. Z. Murad, and R. Haddad, "Compressive strength prediction of lightweight short columns at elevated temperature using gene expression programing and artificial neural network," Journal of Civil Engineering and Management, vol. 26, no. 2, pp. 189-199, 2020.

[24] A. Behnood and E. M. Golafshani, "Predicting the compressive strength of silica fume concrete using hybrid artificial neural network with multi-objective grey wolves," Journal of Cleaner Production, vol. 202, pp. 54-64, 2018.

[25] A. Sadrmomtazi, J. Sobhani, and M. A. Mirgozar, "Modeling compressive strength of EPS lightweight concrete using regression, neural network and ANFIS," Construction and Building Materials, vol. 42, pp. 205-216, 2013.

[26] A. Öztaş, M. Pala, M. Bhatti et al., "Predicting the compressive strength and slump of high strength concrete using neural network," Construction and Building Materials, vol. 20, no. 9, pp. 769-775, 2006.

[27] T. Nguyen, A. Kashani, T. Ngo, and S. Bordas, "Deep neural network with high-order neuron for the prediction of foamed concrete strength," Computer-Aided Civil and Infrastructure Engineering, vol. 34, no. 4, pp. 316-332, 2019.

[28] M. A. Getahun, S. M. Shitote, and Z. C. Abiero Gariy, "Artificial neural network based modelling approach for strength prediction of concrete incorporating agricultural and construction wastes," Construction and Building Materials, vol. 190, pp. 517-525, 2018.

[29] M. Oltean and C. Groşan, "Evolving evolutionary algorithms using multi expression programming," in European Conference on Artificial LifeSpringer, Berlin, Germany, 2003.

[30] A. H. Gandomi and D. A. Roke, "Assessment of artificial neural network and genetic programming as predictive tools," Advances in Engineering Software, vol. 88, pp. 63-72, 2015.

[31] M. F. Javed, M. N. Amin, M. I. Shah et al., "Applications of gene expression programming and regression techniques for estimating compressive strength of bagasse ash based concrete," Crystals, vol. 10, no. 9, p. 737, 2020.

[32] M. Oltean and C. Grosan, "A comparison of several linear genetic programming techniques," Complex Systems, vol. 14, no. 4, pp. 285-314, 2003.

[33] M. Oltean and D. Dumitrescu, "Multi expression programming," Journal of Genetic Programming and Evolvable Machines, Kluwer, New York, NY, USA, 2002.

[34] A. H. Gandomi, A. Faramarzifar, P. G. Rezaee, A. Asghari, and S. Talatahari, "New design equations for elastic modulus of concrete using multi expression programming," Journal of
Civil Engineering and Management, vol. 21, no. 6, pp. 761-774, 2015.

[35] S. Sharifi, S. Abrishami, and A. H. Gandomi, "Consolidation assessment using multi expression programming," Applied Soft Computing, vol. 86, Article ID 105842, 2020.

[36] J. Kennedy and R. Eberhart, "Particle swarm optimization," in Proceedings of ICNN'95-international Conference on Neural Networks, IEEE, Perth, WA, Australia, December 1995.

[37] C. Qi, A. Fourie, and Q. Chen, "Neural network and particle swarm optimization for predicting the unconfined compressive strength of cemented paste backfill," Construction and Building Materials, vol. 159, pp. 473-478, 2018.

[38] F. Marini and B. Walczak, "Particle swarm optimization (PSO). A tutorial," Chemometrics and Intelligent Laboratory Systems, vol. 149, pp. 153-165, 2015.

[39] R. Srinivasan and K. Sathiya, "Experimental study on bagasse ash in concrete," International Journal for Service Learning in Engineering, Humanitarian Engineering and Social Entrepreneurship, vol. 5, no. 2, pp. 60-66, 2010.

[40] J. A. Patel and D. Raijiwala, "Experimental study on use of sugar cane bagasse ash in concrete by partially replacement with cement," International Journal of Innovative Research in Science, Engineering and Technology, vol. 4, no. 4, pp. 22282232, 2015.

[41] D. Neeraja and K. Kiran, "Experimental study on strength properties of concrete by partial replacement of cement with sugarcane bagasse ash," Nature Environment and Pollution Technology, vol. 13, no. 3, p. 629, 2014.

[42] K. Ganesan, K. Rajagopal, and K. Thangavel, "Evaluation of bagasse ash as supplementary cementitious material," Cement and Concrete Composites, vol. 29, no. 6, pp. 515-524, 2007.

[43] T. Subramani and M. Prabhakaran, "Experimental study on bagasse ash in concrete," International Journal of Application or Innovation in Engineering \& Management (IJAIEM), vol. 4, no. 5, pp. 163-172, 2015.

[44] S. Rukzon and P. Chindaprasirt, "Utilization of bagasse ash in high-strength concrete," Materials \& Design, vol. 34, pp. 45-50, 2012.

[45] G. C. Cordeiro, R. D. Toledo Filho, L. M. Tavares, and E. d. M. R. Fairbairn, "Ultrafine grinding of sugar cane bagasse ash for application as pozzolanic admixture in concrete," Cement and Concrete Research, vol. 39, no. 2, pp. 110-115, 2009.

[46] T. S. Kumar, K. Balaji, and K. Rajasekhar, "Assessment of sorptivity and water absorption of concrete with partial replacement of cement by sugarcane bagasse ash (SCBA) and silica fume," International Journal of Applied Engineering Research, vol. 11, no. 3, pp. 5747-5752, 2016.

[47] N.-u. Amin, "Use of bagasse ash in concrete and its impact on the strength and chloride resistivity," Journal of Materials in Civil Engineering, vol. 23, no. 5, pp. 717-720, 2011.

[48] B. Hailu and A. Dinku, "Application of sugarcane bagasse ash as a partial cement replacement material," Zede Journal, vol. 29, pp. 1-12, 2012.

[49] S. A. Mangi, J. Norwati, H. A. Abdullah et al., "Utilization of sugarcane bagasse ash in concrete as partial replacement of cement," in IOP Conference Series: Materials Science and Engineeringvol. 271, 2017.

[50] S. W. Dhengare, S. Raut, B. Vijay et al., "Investigation into utilization of sugarcane bagasse ash as supplementary cementitious material in concrete," International Journal, vol. 109, 2015.

[51] A. A. E. Hussein, "Compressive strength and microstructure of sugar cane bagasse ash concrete," Research Journal of 
Applied Sciences, Engineering and Technology, vol. 7, no. 12, pp. 2569-2577, 2014.

[52] M. V. S. Reddy, "Utilization of sugarcane bagasse ash (SCBA) in concrete by partial replacement of cement," IOSR Journal of Mechanical and Civil Engineering, vol. 12, no. 6, pp. 12-16, 2015.

[53] K. Ganesan, K. Rajagopal, and K. Thangavel, "Evaluation of bagasse ash as corrosion resisting admixture for carbon steel in concrete," Anti-Corrosion Methods and Materials, vol. 54, 2007.

[54] M. Yashwanth, G. B. Avinash, B. G. N. Kumar et al., “An experimental study on alternative cementitious materials: bagasse ash as partial replacement for cement in structural lightweight concrete," Indian Concrete Journal, vol. 91, p. 51, 2017.

[55] N. Shafiq, A. Hussein, F. Nuruddin et al., "Effects of sugarcane bagasse ash on the properties of concrete," in Engineering Sustainabilityvol. 171, 2016.

[56] K. L. Priya and R. Ragupathy, "Effect of sugarcane bagasse ash on strength properties of concrete," International Journal of Research in Engineering and Technology, vol. 5, no. 4, pp. 159-164, 2016.

[57] S. Praveenkumar and G. Sankarasubramanian, "Mechanical and durability properties of bagasse ash-blended high-performance concrete," SN Applied Sciences, vol. 1, no. 12, p. $1664,2019$.

[58] Q. Xu, T. Ji, N. Wu et al., "Characteristics and applications of sugar cane bagasse ash waste in cementitious materials," Materials, vol. 12, no. 1, p. 39, 2019.

[59] J. C. Arenas-Piedrahita, P. Montes-García, J. M. MendozaRangel, H. Z. López Calvo, P. L. Valdez-Tamez, and J. Martínez-Reyes, "Mechanical and durability properties of mortars prepared with untreated sugarcane bagasse ash and untreated fly ash," Construction and Building Materials, vol. 105, pp. 69-81, 2016.

[60] G. C. Cordeiro, R. D. Toledo Filho, L. M. Tavares, and E. M. R. Fairbairn, "Experimental characterization of binary and ternary blended-cement concretes containing ultrafine residual rice husk and sugar cane bagasse ashes," Construction and Building Materials, vol. 29, pp. 641-646, 2012.

[61] D. J. Elwell and G. Fu, Compression Testing of Concrete: Cylinders vs. Cubes, TRID, Washington, DC, USA, 1995.

[62] R. Siddique and G. Singh, "Utilization of waste foundry sand (WFS) in concrete manufacturing," Resources, Conservation and Recycling, vol. 55, no. 11, pp. 885-892, 2011.

[63] A. ACI, 318-11 ACI Building Code Requirements for Structural Concrete and Commentary, American Concrete Institute, Farmington Hills, MI, USA, 2011.

[64] Australia, S., Australian standard for concrete structures AS 3600-2001. Australia, 175pp, 2001.

[65] Standard, B., Eurocode 2: Design of Concrete Structures-Part 1-1: General rules and rules for buildings, 2004: p. 230.

[66] JSCE, Standard Specifications for Concrete Structures, Structural Performance Verification, Tokyo, Japan, 2007.

[67] New Zealand Standard, Concrete Structures Standard, NZS 3101: 2006 The Design of Concrete Structures, New Zealand Standard, Wellington, NZ, Oceania, 2006.

[68] S. M. Mousavi, A. H. Gandomi, A. H. Alavi, and M. Vesalimahmood, "Modeling of compressive strength of HPC mixes using a combined algorithm of genetic programming and orthogonal least squares," Structural Engineering and Mechanics, vol. 36, no. 2, pp. 225-241, 2010.
[69] I. Azim, "Prediction model for compressive arch action capacity of RC frame structures under column removal scenario using gene expression programming," in StructuresElsevier, Amsterdam, Netherlands, 2020.

[70] A. H. Gandomi, A. H. Alavi, M. R. Mirzahosseini, and F. M. Nejad, "Nonlinear genetic-based models for prediction of flow number of asphalt mixtures," Journal of Materials in Civil Engineering, vol. 23, no. 3, pp. 248-263, 2011.

[71] M. Despotovic, V. Nedic, D. Despotovic, and S. Cvetanovic, "Evaluation of empirical models for predicting monthly mean horizontal diffuse solar radiation," Renewable and Sustainable Energy Reviews, vol. 56, pp. 246-260, 2016.

[72] J. Zhang, Y. Huang, G. Ma, J. Sun, and B. Nener, "A metaheuristic-optimized multi-output model for predicting multiple properties of pervious concrete," Construction and Building Materials, vol. 249, Article ID 118803, 2020.

[73] Y. Sun, "Development of an ensemble intelligent model for assessing the strength of cemented paste backfill," Advances in Civil Engineering, vol. 2020, Article ID 1643529, 6 pages, 2020.

[74] S. Xu, X. An, X. Qiao, L. Zhu, and L. Li, "Multi-output leastsquares support vector regression machines," Pattern Recognition Letters, vol. 34, no. 9, pp. 1078-1084, 2013.

[75] K. S. Raju, "Support Vector Machine with k-fold cross validation model for software fault prediction," International Journal of Pure and Applied Mathematics, vol. 118, pp. 321334, 2018.

[76] R. Kohavi, A Study of Cross-Validation and Bootstrap for Accuracy Estimation and Model SelectionIJCAI, Montreal, Canada, 1995.

[77] G. C. Cordeiro, R. D. Toledo Filho, and E. M. R. Fairbairn, "Effect of calcination temperature on the pozzolanic activity of sugar cane bagasse ash," Construction and Building Materials, vol. 23, no. 10, pp. 3301-3303, 2009.

[78] S. A. Memon, S. Khan, W. Israr et al., "Evaluating the effect of calcination and grinding of corn stalk ash on pozzolanic potential for sustainable cement-based materials," Advances in Materials Science and Engineering, vol. 2020, Article ID 1619480, 13 pages, 2020.

[79] A. Bahurudeen and M. Santhanam, "Influence of different processing methods on the pozzolanic performance of sugarcane bagasse ash," Cement and Concrete Composites, vol. 56, pp. 32-45, 2015.

[80] P. Jagadesh, A. Ramachandramurthy, R. Murugesan, and K. Sarayu, "Micro-Analytical studies on sugar cane bagasse ash," Sadhana, vol. 40, no. 5, pp. 1629-1638, 2015.

[81] L. M. S. Souza, "Influence of initial $\mathrm{CaO} / \mathrm{SiO} 2$ ratio on the hydration of rice husk ash-Ca $(\mathrm{OH}) 2$ and sugar cane bagasse ash-Ca (OH) 2 pastes," Química Nova, vol. 37, no. 10, pp. 1600-1605, 2014.

[82] G. C. Cordeiro, R. D. Toledo Filho, L. M. Tavares, and E. M. R. Fairbairn, "Pozzolanic activity and filler effect of sugar cane bagasse ash in Portland cement and lime mortars," Cement and Concrete Composites, vol. 30, no. 5, pp. 410-418, 2008.

[83] P. C. Macedo, "Performance of mortars produced with the incorporation of sugar cane bagasse ash," Revista Ingeniería de Construcción, vol. 29, no. 2, pp. 187-199, 2014.

[84] A. Gholampour, A. H. Gandomi, and T. Ozbakkaloglu, "New formulations for mechanical properties of recycled aggregate concrete using gene expression programming," Construction and Building Materials, vol. 130, pp. 122-145, 2017.

[85] I. E. Frank and R. Todeschini, The Data Analysis Handbook, Elsevier, Amsterdam, Netherlands, 1994. 
[86] A. Golbraikh and A. Tropsha, "Beware of q2!" Journal of Molecular Graphics and Modelling, vol. 20, no. 4, pp. 269-276, 2002.

[87] P. P. Roy and K. Roy, "On some aspects of variable selection for partial least squares regression models," QSAR \& Combinatorial Science, vol. 27, no. 3, pp. 302-313, 2008.

[88] H. Du, "Properties of ultra-lightweight cement composites with nano-silica," Construction and Building Materials, vol. 199, pp. 696-704, 2019. 